\title{
Axonal Regeneration and Functional Recovery after Complete Spinal Cord Transection in Rats by Delayed Treatment with Transplants and Neurotrophins
}

\author{
Jean V. Coumans, Ted Tai-Sen Lin, Hai Ning Dai, Linda MacArthur, Marietta McAtee, Carmen Nash, and \\ Barbara S. Bregman
}

Department of Neuroscience, Georgetown University Medical Center, Washington, DC 20007

Little axonal regeneration occurs after spinal cord injury in adult mammals. Regrowth of mature CNS axons can be induced, however, by altering the intrinsic capacity of the neurons for growth or by providing a permissive environment at the injury site. Fetal spinal cord transplants and neurotrophins were used to influence axonal regeneration in the adult rat after complete spinal cord transection at a midthoracic level. Transplants were placed into the lesion cavity either immediately after transection (acute injury) or after a 2-4 week delay (delayed or chronic transplants), and either vehicle or neurotrophic factors were administered exogenously via an implanted minipump. Host axons grew into the transplant in all groups. Surprisingly, regeneration from supraspinal pathways and recovery of motor function were dramatically increased when transplants and

In the adult CNS, there is a limited capacity for axonal regeneration after injury. Although some axonal regrowth occurs after spinal cord injury early in development (Keirstead et al., 1995, 1997; Nicholls and Saunders, 1996), this capacity for regrowth decreases as the age of the animal at the time of injury increases (Bregman and Goldberger, 1982; Bregman et al., 1989). Spinal cord transection early in development in embryonic chicks (Hasan et al., 1993; Keirstead et al., 1995, 1997) and opossum (Nicholls and Saunders, 1996) show some axonal growth across the transection site. This occurs during a critical window early in development, however, during initial axonal elongation and before the onset of inhibitory influences in the CNS environment.

Alterations in both the intrinsic properties of neurons and characteristics of the CNS environment likely contribute to a decreased capacity of the mature CNS for regrowth after injury. For example, as the CNS matures, there is decreased expression of growth-associated genes in neurons (Fitzgerald et al., 1991; Chong et al., 1992; Herdegen et al., 1997), the appearance of

Received April 2, 2001; revised Sept. 12, 2001; accepted Sept. 12, 2001.

This work was supported by National Institutes of Health Grants NS 27054 and NS 19259 and in part by grants from the International Spinal Research Trust and the Daniel Heumann Fund for Spinal Cord Research. J.V.C. and T.T.-S.L were supported in part by Training Grant T32 HD 07459 from the National Center for Medical Rehabilitation Research. Neurotrophins were generously supplied by Regeneron Pharmaceuticals (Tarrytown, NY).

J.V.C. and T.T.-S.L contributed equally to this work.

Correspondence should be addressed to Dr. Barbara S. Bregman, Department of Neuroscience, Georgetown University Medical Center, 3970 Reservoir Road NW, Washington, DC 20007. E-mail: bregmanb@georgetown.edu.

J. V. Coumans' present address: Department of Neurosurgery, Cleveland Clinic, Cleveland, $\mathrm{OH}$.

T. T.-S. Lin's present address: London School of Hygiene/London School of Economics, London, UK.

Copyright (C) 2001 Society for Neuroscience $\quad 0270-6474 / 01 / 219334-11 \$ 15.00 / 0$ neurotrophins were delayed until 2-4 weeks after transection rather than applied acutely. Axonal growth back into the spinal cord below the lesion and transplants was seen only in the presence of neurotrophic factors. Furthermore, the restoration of anatomical connections across the injury site was associated with recovery of function with animals exhibiting plantar foot placement and weight-supported stepping. These findings suggest that the opportunity for intervention after spinal cord injury may be greater than originally envisioned and that CNS neurons with long-standing injuries can reinitiate growth, leading to improvement in motor function.

Key words: spinal cord injury; CNS regeneration; functional recovery; neurotrophins; fetal transplants; chronic injury myelin-associated inhibitors of axonal growth (Caroni and Schwab, 1988; Savio and Schwab, 1990; Schwab and Schnell, 1991; McKerracher et al., 1994; Davies et al., 1997), and alterations in astrocytes and extracellular matrix molecules that restrict axonal growth (McKeon et al., 1991; Pindzola et al., 1993; Mukhopadhyay et al., 1994; Fitch and Silver, 1997b). Interventions that improve neuronal survival or reduce the exposure of axons to inhibitors can improve regrowth after injury, demonstrating that the capacity for CNS regeneration in the adult exists under certain experimental conditions.

Previous work in our laboratory and by others has used fetal tissue transplants to provide permissive conditions for axonal growth. After complete spinal cord transection in the newborn rat or kitten, supraspinal projections to the spinal cord caudal to the lesion are abolished (Bregman, 1987b; Howland et al., 1995; Miya et al., 1997). Transplants of fetal spinal cord tissue into the lesion site, however, restore some supraspinal projections, leading to improved locomotor function (Howland et al., 1995; Miya et al., 1997). After spinal cord hemisection and transplantation in the adult (despite the presence of a fetal CNS environment), host axons regenerate into the transplant but terminate near the hosttransplant border (Bregman et al., 1989, 1997a,b; Jakeman and Reier, 1991). Exogenous application of neurotrophic factors increases the intrinsic capacity of mature neurons for regrowth. We showed that, after spinal cord hemisection and transplant in the adult, exogenous administration of brain-derived neurotrophic factor (BDNF) or neurotrophin-3 (NT-3) increases supraspinal axonal growth within the transplant (Bregman et al., 1997b), prevents the atrophy of axotomized supraspinal neurons (Bregman et al., 1998), and increases the expression of regeneration- 
associated genes within the cell bodies of the injured axons (Broude et al., 1997, 1999).

The aforementioned studies have involved interventions at the time of the initial injury. Here we report that both the amount of axonal regrowth and the extent of recovery of function are dramatically increased when transplants and neurotrophins are administered 2-4 weeks after a spinal cord transection rather than immediately after injury. Axonal regrowth from both propriospinal and supraspinal neurons is increased within the transplant and the host cord caudal to the lesion. Animals that receive a delayed transplant and neurotrophins show significant improvement in locomotion, including recovery of weight-supported plantar stepping on both treadmill and over-ground tasks (stair climbing). Thus, paradoxically, delaying treatment with transplants and exogenous neurotrophic factors after spinal cord injury results in more permissive conditions for spinal cord regeneration and functional recovery.

\section{MATERIALS AND METHODS}

Surgical procedures: transection and transplantation. Adult female Sprague Dawley rats (6-8 weeks of age, 200-250 gm; Zivic Inc., Zelienople, PA) were used in four surgical paradigms. In the first, 52 rats received complete spinal cord transections at the T6-T8 spinal levels using procedures described previously (Bregman, 1987b; Bregman and McAtee, 1993). Briefly, after laminectomy, the dura was opened, and the spinal cord was transected using iridectomy scissors. Vacuum suction was used to clean the most lateral recesses of the canal. The severed ends of the cord typically retracted 3-5 $\mathrm{mm}$ and were inspected under a surgical microscope to ensure complete transection. Animals received whole pieces of embryonic day 14 (E14) fetal spinal cord tissue (Bregman and McAtee, 1993), which was placed into the transection cavity to ensure that the entire gap was bridged by transplant tissue. Typically, four to six entire segments of fetal spinal cord were necessary. Saline-soaked gel foam was placed on top of the transplant tissue, and the muscles and skin were closed in layers. In the second surgical paradigm, at the time of spinal cord transection, 43 animals received saline-soaked gel foam instead of transplant. Durafilm was placed over the injury site with the rostral and caudal ends tucked under remaining laminas, and a piece of subcutaneous fat was placed over the durafilm. Two weeks after the initial transection, the wound was reopened, the durafilm was removed, and the scar tissue and bone were removed with iridectomy scissors and suction, starting from the middle of the injury until normal-appearing spinal cord was visible both caudally and rostrally. Typically, the separation between rostral and caudal spinal cord at the transection site was 7-9 $\mathrm{mm}$ after the removal of the glial scar. Embryonic spinal cord (E14) was placed in the cavity as described above, except that 8-11 segments were used. A third group was similar to the second group, except that the animals received fetal spinal cord 4 weeks after spinal cord transection. A fourth control group (38 rats) received transection without transplant of fetal tissue. After surgery, care was taken to prevent dehydration by hydrating animals with up to $20 \mathrm{cc} / \mathrm{d}$ with D5 lactated Ringer's solution or D5 normal saline injected intraperitoneally. Bladders were manually expressed twice per day as necessary. Animals received sulfamethoxazole $(4 \mathrm{mg} / 100 \mathrm{gm})$-trimethoprim $(0.8 \mathrm{mg} / 100 \mathrm{gm})$ twice per day orally to prevent infection. Food was provided on the cage floor, and the rats had no difficulty reaching their water bottles. Supplemental oral feedings of STAT hypercaloric formula were given as necessary.

Neurotrophin administration. In both the acute and delayed transplant groups, Alzet osmotic minipumps (Alza, Mountain View, CA) were inserted subcutaneously at the time of fetal tissue transplantation. Pumps delivered saline or neurotrophic factors, human recombinant BDNF (2 $\mathrm{mg} / \mathrm{ml})$, or human recombinant NT-3 $(1 \mathrm{mg} / \mathrm{ml})$ at a rate of $0.5 \mu \mathrm{l} / \mathrm{hr}$ continuously for $14 \mathrm{~d}$. The pumps delivered their contents directly to the transplant tissue via a polyethylene catheter attached to the pump. An opening cut into the side of the catheter was aligned on top of the transplant site in contact with the overlying gel foam. The minipump and catheter were secured with sutures, and the wound was closed. In the control group, 23 rats received saline only, eight received BDNF, and seven received NT-3. In the rats that received an acute transplant, 13, 22, and 17 received saline, NT-3, and BDNF, respectively. In the rats that received a delayed transplant, 7, 19, and 17 received saline, NT-3, and
BDNF, respectively. All minipumps were removed at the end of 2 weeks. Neurotrophins were a generous gift from Regeneron Pharmaceuticals (Tarrytown, NY).

Immunohistochemistry. Animals were anesthetized and perfused with

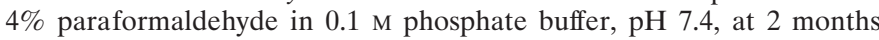
after the second surgery. Serial cryosections of spinal cord $(20 \mu \mathrm{m})$ were cut in a transverse or longitudinal plane and thaw-mounted onto SuperFrost Plus slides (Fisher Scientific, Springfield, NJ). Coronal sections of brains $(20 \mu \mathrm{m})$ were cut in a 1:6 series and thaw-mounted onto slides.

Antibodies against serotonin [5-hydroxytryptamine (5-HT)] were used to visualize raphe-spinal projections within the host cord and transplant using techniques from procedures described in detail previously (Bregman, 1987a,b). The primary antibody used was rabbit anti-serotoninbovine serum albumin conjugate (DiaSorin, Stillwater, MN) at a 1:3000 dilution. Sections were incubated in primary antibody overnight at room temperature, followed by a $1 \mathrm{hr}$ incubation with a biotinylated secondary antibody and 90 min with streptavidin (ABC, VectaStain Elite; Vector Laboratories, Burlingame, CA) before developing in diaminobenzidine with nickel enhancement. Antibodies against Fluoro-Gold were used to verify the presence of Fluoro-Gold in cells when the fluorescence was less visible (1:1000 dilution; Chemicon, Temecula, CA).

Neuroanatomical tracing. Anterograde and retrograde neuroanatomical tracing was used to determine the extent to which supraspinal neurons regrew axons to reach spinal cord segments caudal to the transection. The animals for the tracing were selected from operates without explicit selection criteria other than they were healthy and had maintained their weight. The investigator was blinded to the behavioral analysis of the animal. For retrograde tracing, the spinal cord was exposed by laminectomy below the transection site, and gel foam pieces soaked with $2 \%$ Fluoro-Gold (Fluorochrome Inc, Englewood, NJ) in saline were placed bilaterally into the cord $10 \mathrm{~mm}$ below the caudal transection site 1 week before the animals were killed. For anterograde tracing, Fluoro-Ruby (5 $\mu \mathrm{l}$ of a $10 \%$ solution in saline; tetramethylrhodamine dextran, 10,000 molecular weight; Molecular Probes, Eugene, OR) was injected bilaterally into the cortex, $10 \mathrm{~d}$ before the animals were killed, to label corticospinal axons. Sections were viewed under fluorescent illumination at 365 and $485 \mathrm{~nm}$ for Fluoro-Gold and Fluoro-Ruby, respectively. The injection sites, lesions, and transplants were examined in all animals to ensure that there was no unintended diffusion of tracer into either the transplant or the host spinal cord rostral to the transplant. None of the animals included in this study had any spread of tracer. In all animals, the rostrocaudal and transverse extent of both the lesion site and the transplant apposition were examined by cresyl violet staining and serial reconstruction of the lesion site every $120 \mu \mathrm{m}$ (longitudinal plane) using an aus Jena microprojector and a Zeiss (Oberkochen, Germany) microscope. All animals included in the anatomical and behavioral results had transplants in physical apposition with host spinal cord at both the rostral and caudal host-transplant interface.

Quantitative image analysis. For quantification of axon growth, the spinal cord containing lesion, transplant, and up to $10 \mathrm{~mm}$ caudal to lesion was cut longitudinally in a 1:6 series. Sections on every sixth slide were analyzed for 5-HT immunoreactivity generating 18-22 sections per animal for analysis. The immunolabeled fibers were captured digitally and analyzed using Sigma Scan (Jandel Scientific, San Rafael, CA). Fiber length, location (white vs gray), number of fiber clusters, and the number of fiber branch points within a cluster were determined. The KruskalWallis ANOVA on ranks was used to establish that a given variable differed between treatment groups. This was followed by Mann-Whitney $U$ tests to identify which group(s) accounted for the difference.

Behavioral analysis. The methods used for quantitative analysis of sensorimotor function after spinal cord injury have been described in detail previously (Kunkel-Bagden and Bregman, 1990; Bregman et al., 1993, 1995; Kunkel-Bagden et al., 1993; Bregman, 1994; Miya et al., 1997) and are described briefly below. Motor behavior was assessed with three tasks: quadrupedal treadmill locomotion, stair climbing, and runway locomotion (both wide and narrow with sides to provide postural support for the rats). For quadrupedal treadmill locomotion, animals were placed in an adjustable Velcro harness fitted between the forelimbs and secured around the upper trunk (to provide partial postural support), with external postural support for the hindquarters provided as needed. After 1 week of training, animals were tested and videotaped $5 \mathrm{~d} /$ week for 2 weeks. The kinematics of the hindlimb during locomotion was documented from videotapes using the Peak Performance Movement Analysis System (Peak Performance Technologies Inc., Englewood, CO). The total number of the hindlimb steps and the number of plantigrade steps 
were counted during $3 \mathrm{~min}$ of continuous treadmill locomotion at a constant speed of $4.7 \mathrm{~m} / \mathrm{min}$. Stair climbing was used to assess overground movement. The number of plantigrade steps was counted (of a total of seven possible stairs) and averaged for four trials of stair climbing. All locomotor testing was conducted without any external sensory stimulation, such as tail pinch.

Qualitative observations of locomotion were made directly and from videotapes of performance during over-ground locomotion (while rats crossed the runway and climbed a stairway) and during quadrupedal locomotion on a treadmill. Particular attention was paid to the extent of hindlimb weight support, hindlimb position during stance and swing, presence or absence of toe drag, and reciprocity of stepping movements. Weight-supported plantigrade stepping on stairs was characterized by (1) plantar food placement to step with the hindlimb in a position to accept weight support, (2) abdomen in up- or mid-position (no contact on step or walking surface), (3) hindlimb weight support (partial or full), (4) symmetrical postural stability, and (5) hindlimb flexion or extension characteristic of a step cycle. Thus, weight-supported plantar steps on stairs was the number of steps in which the rat's entire body was supported above the surface on which it was walking. Weight-supported plantigrade stepping on the treadmill was characterized as follows. Rats were put in a harness to provide postural support. The harness (which was connected to the top of the treadmill by a spring) was lowered such that, when the animals pushed up on their limbs, the harness moved up and down (but not sideways). Thus, weight-supported stepping on the treadmill was characterized by (1) plantar foot placement to treadmill with the hindlimb in a position to accept weight support, (2) movement of the harness up and down as the rat lifted its body, and (3) hindlimb flexion or extension characteristic of a step cycle. It should be noted that Basso, Beattie, Bresnahan (BBB) (Basso et al., 1995) analysis was not used for several reasons: animals received a complete spinal cord transection rather than a thoracic contusion injury (for which the test was developed), and animals required some support for stability, precluding standard methods of BBB analysis. Rather, our tests were modifications of the $\mathrm{BBB}$ scoring to allow us to measure recovery on the stairs and treadmill.

Individuals conducting the behavioral testing were unaware of the identity of the treatment group to which the animals belonged. In addition, after the 2 week testing period was concluded, testing was continued on most of these animals (1-2 d/week for up to 4 months after transection) to be certain that any behavioral improvements observed were maintained and that there was no late improvement in any group of animals.

The animals selected for behavioral analysis were chosen before surgery without explicit selection criteria from the total number of animals prepared for this study. In both acute and delayed transplant groups, daily qualitative analysis of locomotor function began immediately after the transplant. Quantitative behavioral analysis of locomotor function during treadmill locomotion and stair climbing began 4 weeks after transplant. Animals that received a delayed transplant with neurotrophins and that exhibited weight-supported stepping for 5 consecutive days were included in the analysis. Animals that received an acute transplant with neurotrophins, and that showed any weight-supported stepping, were included in the analysis, because none of these animals ever showed weight-supported stepping for 5 consecutive days. ANOVA followed by appropriate post hoc tests (Tukey's multiple comparison and Dunnett's) were used for statistical comparisons of behavioral data.

\section{RESULTS}

\section{Growth of supraspinal axons into transplant tissue}

In adult rats, spinal cord transection permanently abolished all supraspinal axonal projections caudal to the transection. Immunocytochemical visualization for descending serotonergic raphespinal axons revealed that no serotonergic fibers were detected in the spinal cord caudal to the transection by 2 weeks after injury in animals that received transection (TX) only $(n=23)$ and in animals that received transection with neurotrophins [TX plus BDNF $(n=8)$ and TX plus NT-3 $(n=7)]$. Furthermore, no fibers were detected at 4,8 , or 12 weeks after injury under these conditions. Thus, at the time of the reexposure of the spinal cord for delayed transplant, any remaining descending axons had already undergone Wallerian degeneration.
After either acute or delayed spinal cord transplantation (either with or without neurotrophins), the embryonic spinal cord transplants survived, grew, and matured to bridge the gap between the rostral and caudal stumps of the host adult spinal cord, restoring structural integrity across the injury site (Fig. $1 A$ ). A transplant fully bridged the gap created by the transection in $>90 \%$ of the animals in each of the experimental groups, regardless of time of transplant or exogenous neurotrophin support.

In the absence of exogenous neurotrophins, host axons grew into the transplants, but the innervation by descending serotonergic axons was sparse, similar to our previous observations in the spinal cord hemisection model (Fig. $1 B$ ). Host axons were found predominantly near the rostral host-transplant interface and rarely crossed the transplant to reinnervate the spinal cord caudal to the lesion and transplant. In contrast, the exogenous administration of neurotrophins (BDNF or NT-3) increased axonal regrowth within both the transplant (Fig. 1C) and the host spinal cord caudal to the transplant (Figs. 2, 3). Surprisingly, the percentage of animals in which regrowth occurred was greater when the transplant of embryonic spinal cord was delayed by 2 weeks after spinal cord transection. Furthermore, in all animals that received a delayed transplant, the density of supraspinal ingrowth within the transplants was greater than that which occurred in animals that received fetal spinal cord tissue immediately after injury (Fig. 1D).

\section{Growth of supraspinal axons into host spinal cord caudal to transection and transplant}

To address whether the supraspinal fibers that entered the transplant were able to traverse it to reach the caudal host spinal cord, serotonergic fibers caudal to the lesion and transplant were examined. Unexpectedly, there were dramatic increases in both the number of animals with fibers caudal to transplant and increases in axon density, length, and branching in animals that received a delayed transplant and neurotrophins compared with the acute transplant conditions. In the group that received a transplant with neurotrophins immediately after transection, 16 of the 29 animals $(55 \%)$ had visible 5-HT-containing fibers in the host cord caudal to the transplant. In the group that received a transplant with neurotrophins 2 weeks after the transection, 24 of the 27 animals $(89 \%)$ had 5-HT-containing fibers in the host caudal cord $\left(\chi^{2}\right.$; $p=0.013$ ). Furthermore, whereas the serotonergic axons that regrew in the host spinal cord caudal to the transection and transplant in the acute transplant group were scattered, thin, and relatively unbranched (Fig. $2 A$ ), in animals that received a delayed transplant and neurotrophins, the pattern of axonal growth was denser with more branching and with significantly larger and more complex cluster sizes in both gray matter and white matter (Figs. $2 B, 3 B, C$ ). The difference was most pronounced in the gray matter in which the average cluster size and number of branch points per cluster were significantly greater $(p<0.001$ for acute versus delayed for both BDNF and NT-3; Mann-Whitney $U$ test) (Figs. 2, compare $A, B, 3 B, C$ ).

There was also greater long-distance axonal growth in animals that received a delayed transplant with neurotrophins. Supraspinal serotonergic axons were observed not only in the host thoracic spinal cord but also in the lumbar spinal cord in 18 of 24 animals in the delayed transplant group compared with 8 of 16 animals in the acute transplant group. Examination of the mean total fiber length indicated that total axonal growth was more than sixfold greater in white matter and 2.6-fold greater in gray matter in animals that received a delayed transplant ( 2 weeks) compared 


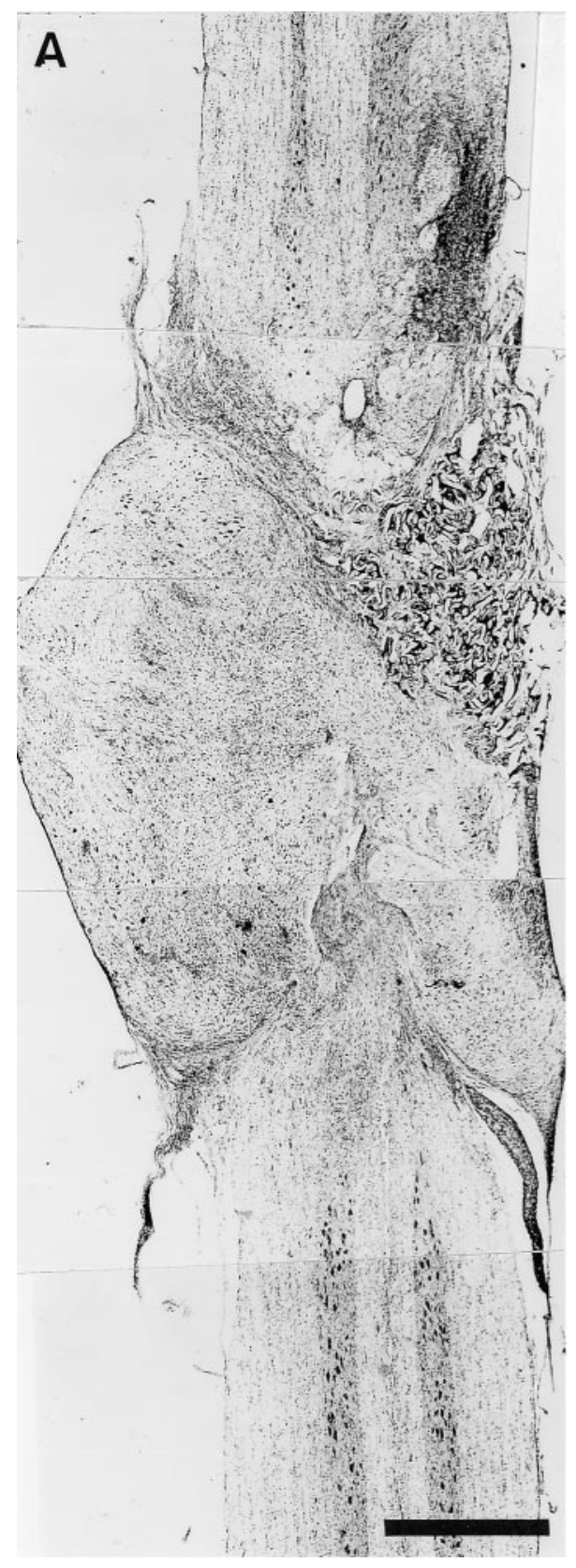

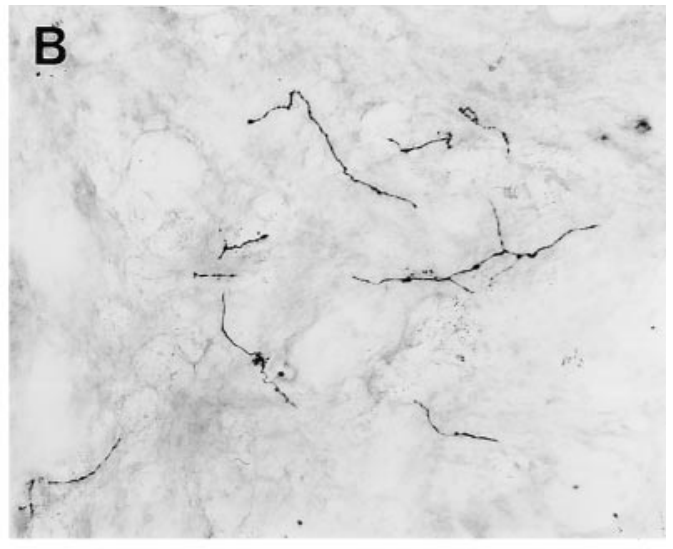
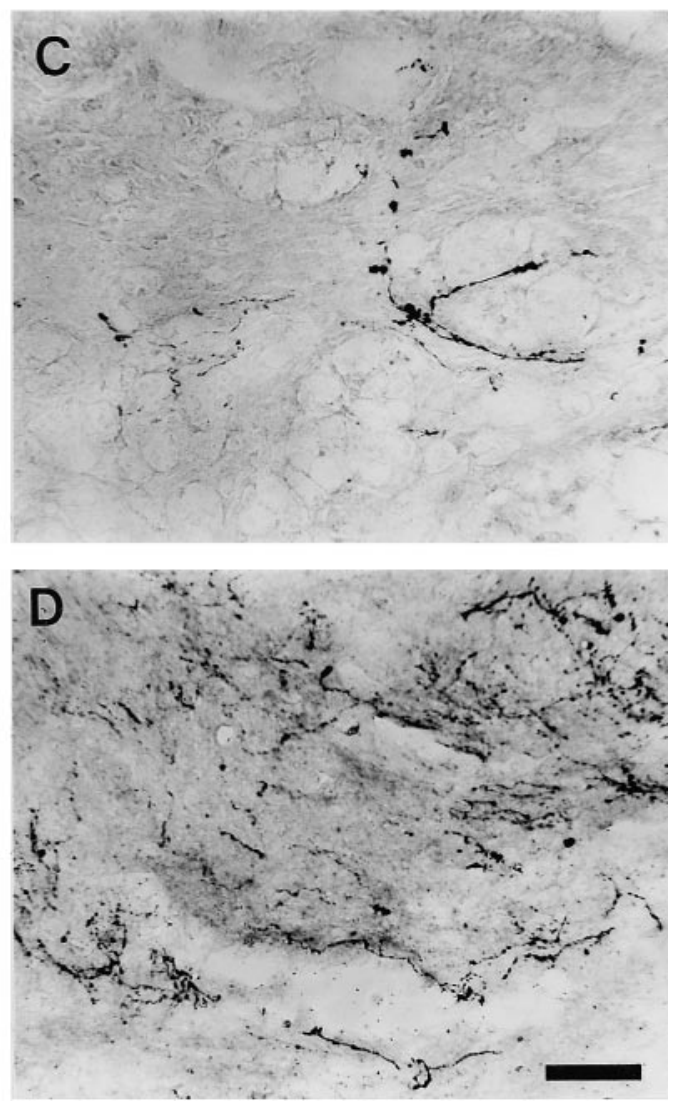

Figure 1. Transplants of fetal spinal cord tissue survived and bridged the gap at the transection site. $A$, Montage of longitudinal cresyl violet-stained sections through the lesion and transplant site. Rostral and caudal host cord are to the top and bottom respectively, and transplant is in the middle. Animals were killed 5 weeks after transplantation. Scale bar, $1 \mathrm{~mm}$. The spinal cord containing lesion and transplant and the caudal segment with an additional $10 \mathrm{~mm}$ of spinal cord was examined. $B-D$, Raphe-spinal axons in longitudinal sections through the transplant were stained for 5-HT. Fibers were detected 7-8 mm from the caudal border of the transplant in the ventral horn gray matter and white matter. $B$, Acute transection and transplant. $C$, Acute transection and transplant with neurotrophins. $D$, Transection with delayed transplant and neurotrophins. Scale bar, $50 \mu \mathrm{m}$. with those that received transplant immediately after injury (Fig. $3 A$ ). In both immediate and delayed groups, axonal growth was greater in the gray matter than in the white matter of the host spinal cord caudal to the transection and transplants.

To determine whether the beneficial effect of delaying transplantation was also observed at longer postinjury intervals, we delayed transplantation by 4 weeks in an additional set of animals $(n=8)$. After a 4 week delay, although fiber length was greater than that observed after acute transplant, it was attenuated by $\sim 50 \%$ in white matter and in gray matter compared with the axonal growth after a 2 week delay and transplantation (Fig. $3 A$ ). Although total axonal length was decreased after a 4 week delay, the complexity of the arbors was similar to that after a 2 week delay (Fig. 3B,C).

\section{Neuroanatomical tracing of regenerated axons}

Retrograde and anterograde neuroanatomical tracing was done to confirm our observations that, in animals that received delayed transplants with exogenous neurotrophins, host supraspinal axons traversed the transection and transplant to reach caudal host spinal cord. Two to 4 months after the initial injury, Fluoro-Gold was placed into the host spinal cord caudal to the lesion (1 week before the animals were killed). None of the transection-only animals (with or without neurotrophins) had any Fluoro-Gold labeling across the lesion site (0 of 12 animals). In animals that received transplant without neurotrophins, fluorescence microscopy revealed intense Fluoro-Gold labeling of neurons in host spinal cord rostral to the transplant in 5 of 10 animals, but these labeled neurons were found only at spinal cord levels (Fig. 4F). There were no detectable Fluoro-Gold-positive cells in any of the brainstem nuclei in any animals that did not receive neurotrophins. In animals that received transplants with neurotrophins, neurons containing Fluoro-Gold were clearly identified within brainstem nuclei (red nucleus, locus ceruleus, raphe nucleus, lateral vestibular nucleus, and reticular formation) (Fig. 4A-E) 

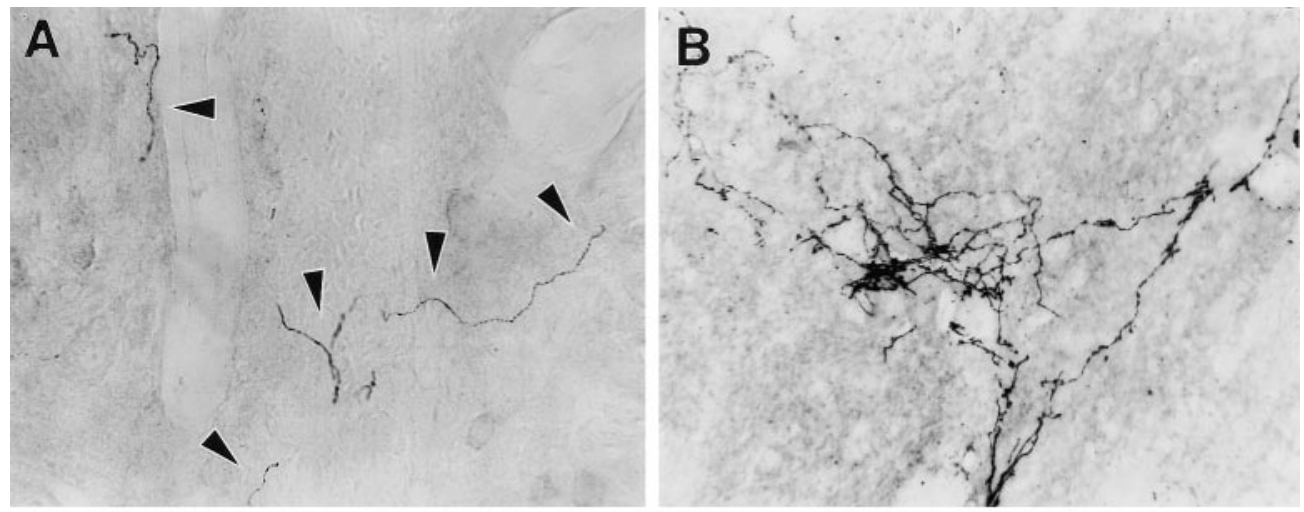

Figure 2. Raphe-spinal axons were able to reenter the host spinal cord caudal to the transplant and enter both gray and white matter. Longitudinal sections through the host spinal cord caudal to the transplant were stained for 5-HT Serotonergic axons that regrew in host spinal cord caudal to transection and transplant in the acute transplant group were scattered, thin, and relatively unbranched. $A$ shows fibers in the gray matter. Delayed transplant and neurotrophins resulted in denser axonal growth with more branching and larger cluster sizes. $B$ shows fibers in the gray matter, and $C$ shows fibers in the white matter. In $A-C$, axons are marked with arrowheads. Scale bar, $50 \mu \mathrm{m}$.

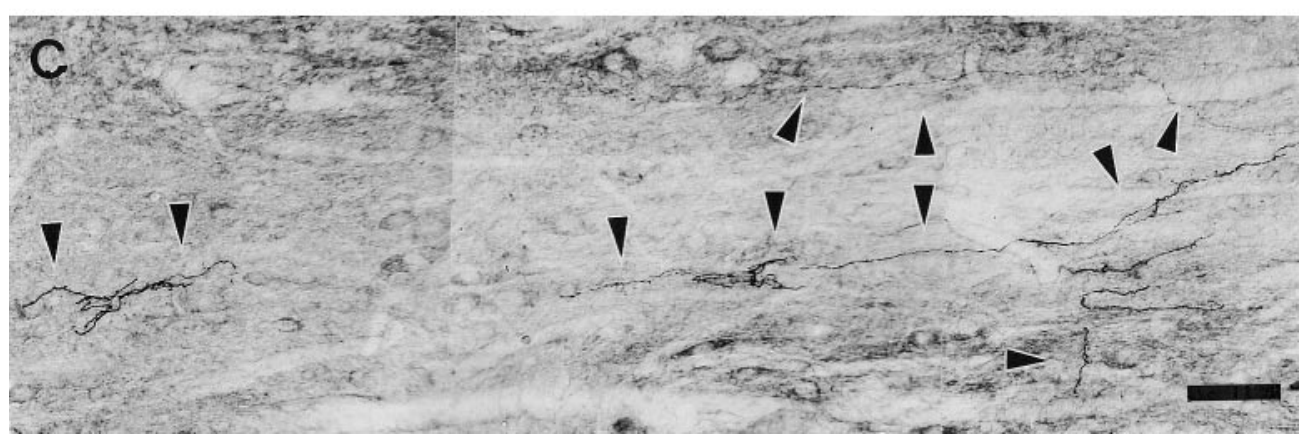

and within layer $\mathrm{V}$ of hindlimb sensorimotor cortex of these animals (data not shown). Fluorescence labeling in these nuclei was confirmed by immunocytochemistry with an antibody against Fluoro-Gold (data not shown).

The presence of Fluoro-Gold in nuclei other than the raphespinal neurons suggested that axonal growth was not restricted to the serotonergic pathways. However, the retrograde labeling of the corticospinal neurons was more scattered than that observed in the brainstem nuclei and did not photograph well. Therefore, to confirm these findings, corticospinal axons were anterograde labeled by injecting Fluoro-Ruby into the motor cortex. FluoroRuby-labeled corticospinal axons extended caudal to the lesion and transplant and down the host thoracic cord in both the gray and white matter (Fig. 5A). Although the corticospinal labeling caudal to the lesion and transplant was sparse, some FluoroRuby-labeled fibers extended as far as the lumbar enlargement (Fig. 5B). Immunocytochemical labeling for noradrenergic axons showed similar patterns of regrowth (data not shown).

\section{Behavioral analysis}

A subset of animals underwent behavioral analysis before being killed to determine whether the anatomical reestablishment of supraspinal and propriospinal input improved locomotor function. Daily observations of locomotor function began immediately after surgery. For the first 3 weeks after surgery, motor behavior was similar in all groups of animals, regardless of presence of transplant or addition of neurotrophins. There was no voluntary hindlimb movement on either the treadmill or runway or any weight-supported stepping. The hindlimbs were dragged passively and maintained in an extended and adducted position, with the dorsal surface of the foot down and digits flexed. All forward movement and weight support was generated by the forelimbs. Differences in motor function began to emerge between groups, however, during the third to fourth week after transplant. Animals that received a delayed transplant with neurotrophins (either 2 or 4 weeks after transection) exhibited partial hindlimb weight support on the runway, with frequent unilateral or bilateral plantar foot placement. Even during step cycles without weight-supported stepping (stair climbing or runway), digits were extended and abducted, and the feet were in complete plantar placement. Extended periods of forelimb-hindlimb coordination during runway walking were seen more frequently in this group than in animals that received a transplant immediately after transection, although all groups required external postural support via a harness or with the addition of "sides" to the runway for this to occur. The reciprocal and bilateral step pattern used by rats that received transplants and neurotrophins 2 weeks after spinal cord transection could be independently sustained throughout a 3 min duration of treadmill quadrupedal locomotion. When rats took weight-supported steps, either on the stairs or over ground, they were coordinated with forelimb movement. Postural control of the tail and hindquarters remained limited with weight, often shifting from one side to the other during locomotion.

At this point, training on the behavioral tasks was conducted for 1 week and animals were tested and videotaped $5 \mathrm{~d}$ /week for 2 weeks. Weight-supported plantar foot placement was examined during treadmill locomotion. Animals that received transplant and neurotrophins 2 weeks after transection showed the most improvement in function. Approximately half of these animals (of 24 total animals) showed some weight-supported plantar stepping. Animals that showed weight-supported stepping for 5 consecutive days ( $n=5$ animals) were included in the quantitative analysis (Fig. 6A). These animals showed the most improvement in motor function of all of the treatment groups. If an animal showed weight-supported plantar stepping but failed to take steps for $5 \mathrm{~d}$ consecutively, it was excluded from the quantitative analysis. The remaining half of the animals did not show weightsupported stepping. Therefore, animals that received delayed transplant and neurotrophins after transection exhibited one of three behaviors: consistent weight-supported stepping ( $\sim 20 \%$ of animals), inconsistent weight-supported stepping ( $\sim 30 \%$ of ani- 
A

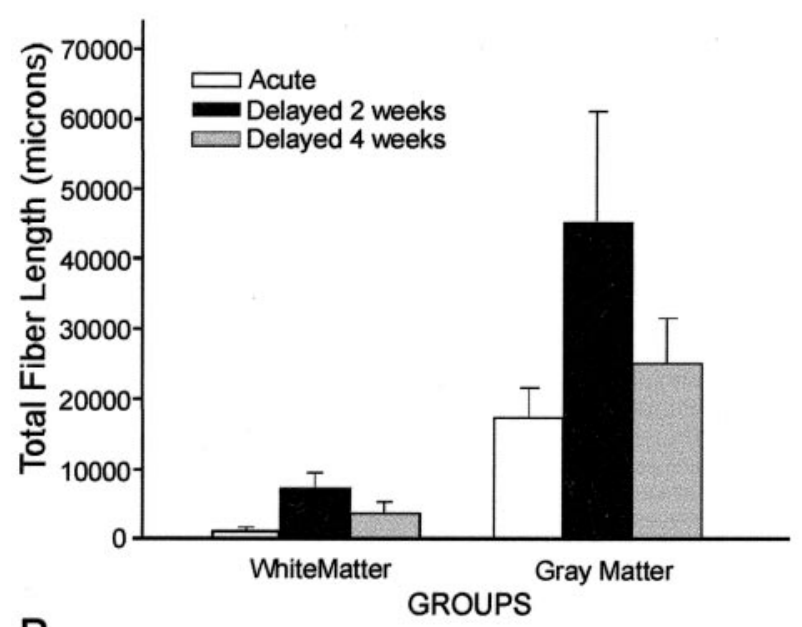

B

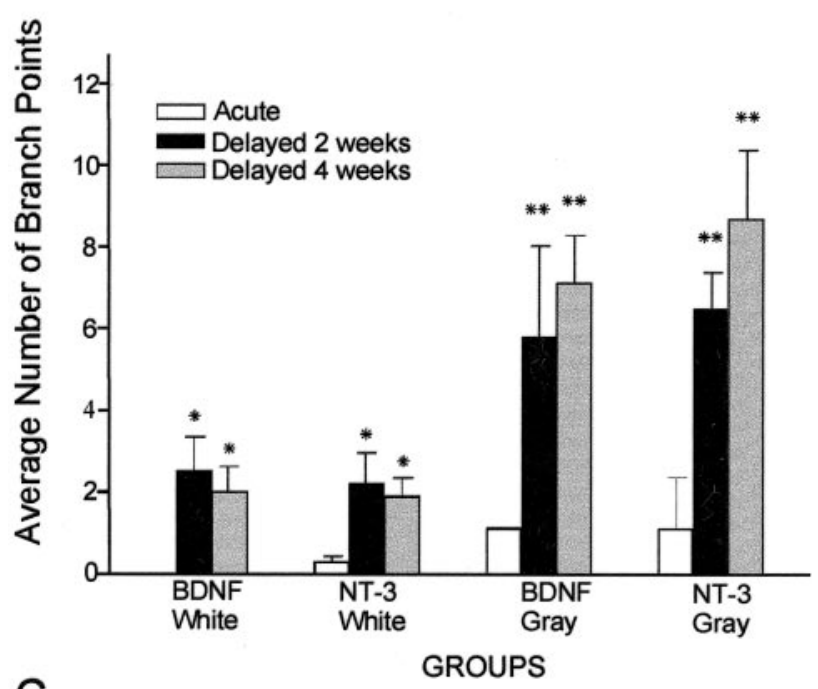

C

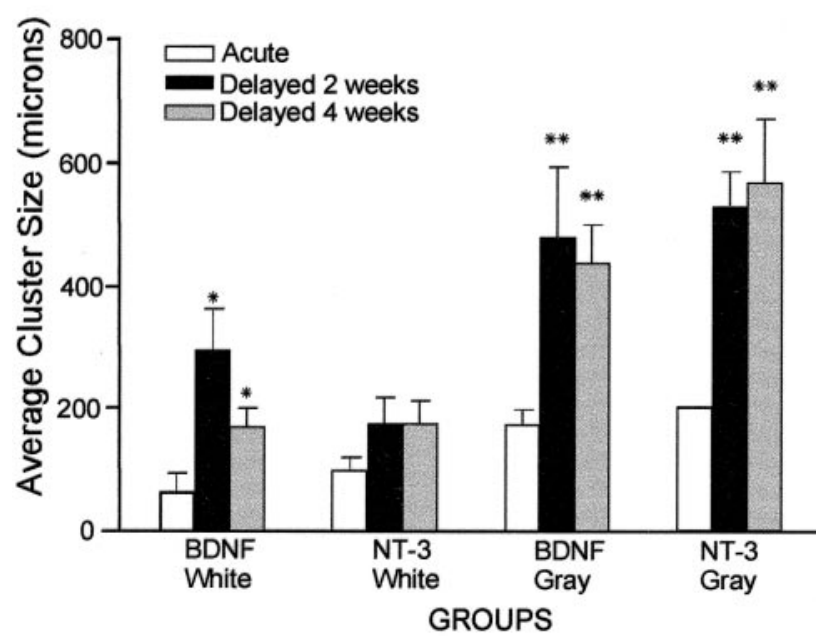

Figure 3. A, Total length of serotonergic fibers per animal was measured over a distance of $10 \mathrm{~mm}$ caudal to the lesion (length is mean $\pm \mathrm{SEM}$ micrometers). A greater total fiber length was observed in the gray matter compared with the white matter $(p=0.004$ for acute; $p<0.001$ for delayed; Mann-Whitney $U$ test). $B$, The average number of branch points was significantly higher in the gray matter in the delayed transplant groups compared with the acute transplant group $\left({ }^{*} p<0.01 ;{ }^{* *} p<0.001\right.$; mals), and no weight-supported stepping ( $\sim 50 \%$ of animals). Animals that received transplant and neurotrophins immediately after spinal cord transection showed some weight-supported plantar stepping ( $n=4$ of 17 animals) (Fig. $6 A$ ), although much less than that seen in animals that received delayed transplant and neurotrophins, and these animals never took steps for 5 consecutive days. Animals that received a transection only $(n=8)$, a transection with transplant only immediately after injury $(n=7)$, or transection with transplant only 2 weeks after surgery $(n=7)$ showed no weight-supported plantar stepping.

The kinematics of hindlimb movement during quadrupedal treadmill locomotion was examined from videotape recordings using the Peak Performance Movement Analysis System. Step cycles were digitized, and the movement pattern was reconstructed. The normal step cycle was characterized by a weightsupported hindlimb stance with easily distinguished beginning stance $(B S)$, middle $(M S)$, and end of stance $(E S)$ phases, with a swing phase in which the hindlimb has no contact with the surface $(M S W)$ (Fig. 6B). Animals that received a transection (with or without transplant) but no neurotrophins dragged their hindlimbs passively and showed no weight support (TX only). In contrast, the step cycles of animals that received a delayed transplant with neurotrophins exhibited a kinematic pattern similar to that of normal animals. Many of the step cycles were characterized by full or partial hindlimb weight-supported stepping on the plantar surface of the foot. Beginning, middle, and end of stance could be distinguished, as could a swing phase in which the hindlimb cleared the surface and the weight was supported by the contralateral limb.

Plantar stepping on stairs was used as an over-ground measure of motor function. Control animals ascend a wide-base staircase comprised of seven steps using $100 \%$ weight-supported steps (Fig. $7 B$ ). Animals that received transections only do not take hindlimb steps (plantar or dorsal) during stair ascension. Postural support of the trunk is replaced by side-lying positioning and abdomen drag (Fig. 7A). All forward propulsion and weight support is generated by the forelimbs. In contrast, animals that received delayed transplants and neurotrophins displayed a dramatic improvement in the number of weight-supported plantar steps (Fig. $7 B$ ). These animals demonstrated more postural trunk support and periods of alternating and reciprocal hindlimb locomotion characterized by weight support through the hindlimb with plantar foot placement (Fig. 7A). Furthermore, these animals were capable of single-limb support with raised abdomens during the middle stance and middle swing phases. In contrast, in all other groups (including animals that received a transection only, transection with immediate transplant with or without neurotrophins, and delayed transplant without neurotrophins), animals showed no weight support on the plantar surface of the foot during stair climbing. Although some did exhibit hindlimb flexion and extension (spinal stepping), this was always without coordination with the forelimbs and without weight support. None of the animals in any of the groups possessed sufficient hindlimb strength and control to descend stairs.

We attempted to correlate the amount of anatomical regrowth (fiber density) to improvements in locomotor function. However,

$\leftarrow$

Mann-Whitney $U$ test). $C$, The average size of serotonergic axon clusters was significantly larger in the gray matter for the delayed transplant group $\left({ }^{* *} p<0.001\right)$ and in the white matter in animals that received BDNF $\left({ }^{*} p<0.01 ;\right.$ Mann-Whitney $U$ test $)$. 

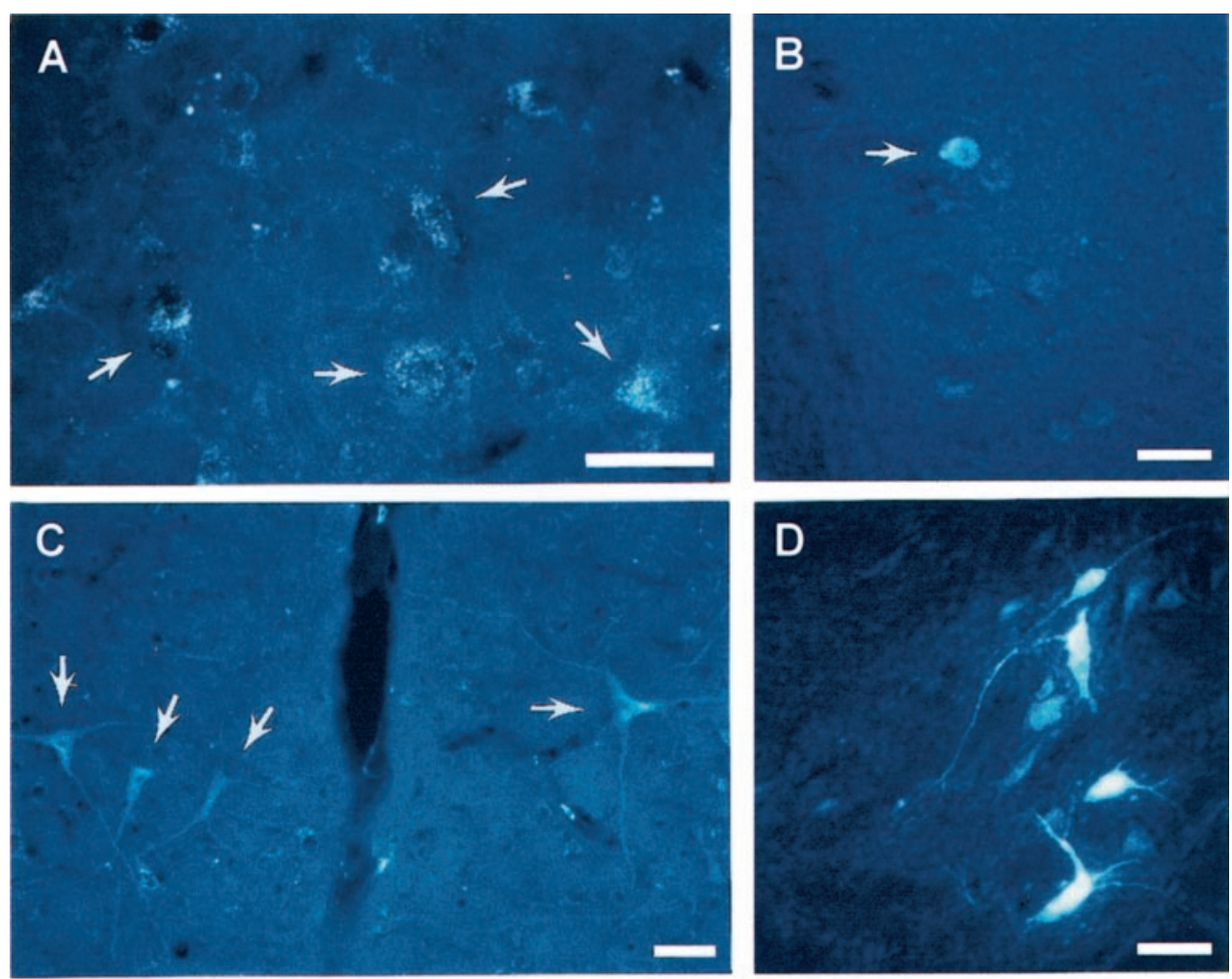

Figure 4. Fluoro-Gold retrograde labeling of regenerated neurons. Neuronal cytoplasm is labeled (arrows) by FluoroGold in transverse sections of the caudal one-third of the red nucleus $(A)$, locus Ceruleus $(B)$, raphe nucleus $(C)$, lateral vestibular nucleus $(D)$, and reticular formation $(E)$. Fluoro-Gold staining is also present in the cytoplasm of spinal neurons rostral to transplant in host cervical cord (longitudinal section) $(F)$ and in the cell bodies of cortical neurons (data not shown). Scale bars, $100 \mu \mathrm{m}$.
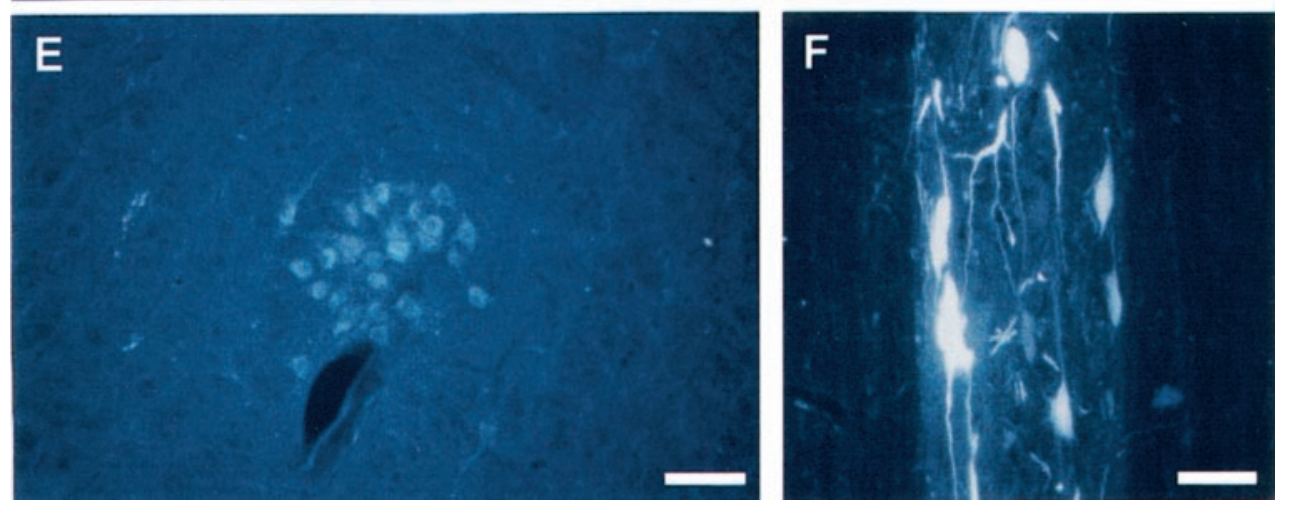

supraspinal fiber regrowth did not directly relate to functional improvement in any immediately obvious manner, other than the most recovery was seen in animals that established supraspinal input to the host cord caudal to the transection (i.e., those animals that received transplants with neurotrophins). Some animals with extensive fiber growth, however, performed worse than animals with sparser growth.

Retransection of the spinal cord rostral to the transplant in animals that showed recovery of function (4 months after the initial lesion) abolished the movements that had recovered (data not shown). There was no subsequent recovery of weightsupported stepping and plantar foot placement on treadmill or on stairs during the subsequent 5 week observation period. The relesioning abolished the supraspinal projections within and caudal to the transplant. This suggests that at least some of the motor recovery observed was dependent on the anatomical connections established through the transplants.

\section{DISCUSSION}

We showed previously that fetal rat spinal cord tissue transplanted into the hemisected or partially lesioned spinal cord of an adult rat, along with BDNF or NT-3 administration, supports the regrowth of supraspinal pathways (Bregman, 1994; Bregman et al., 1998, 1997b). Limited regrowth into the spinal cord caudal to the lesion occurs, however, even when a favorable terrain is present at the lesion site (Reier et al., 1988; Jakeman and Reier, 1991; Bregman, 1994). We demonstrate here that, when the delivery of transplants and neurotrophins is delayed until 2 weeks after spinal cord transection, the amount of axonal growth and the amount of recovery of function are dramatically increased. Under these conditions, both supraspinal and propriospinal projections to the host spinal cord caudal to the transection are reestablished.

Quantitative analysis of fiber growth demonstrated that substantial growth of axons across the transplant into caudal host spinal cord required exogenous administration of either BDNF or NT-3. Without neurotrophins, supraspinal axons rarely crossed through the transplant. The greater axonal growth in the delayed transplant group was reflected in total axonal length, cluster size, and branching, with BDNF and NT-3 showing similar efficacy. Long-distance growth of axons occurred in both the gray and 

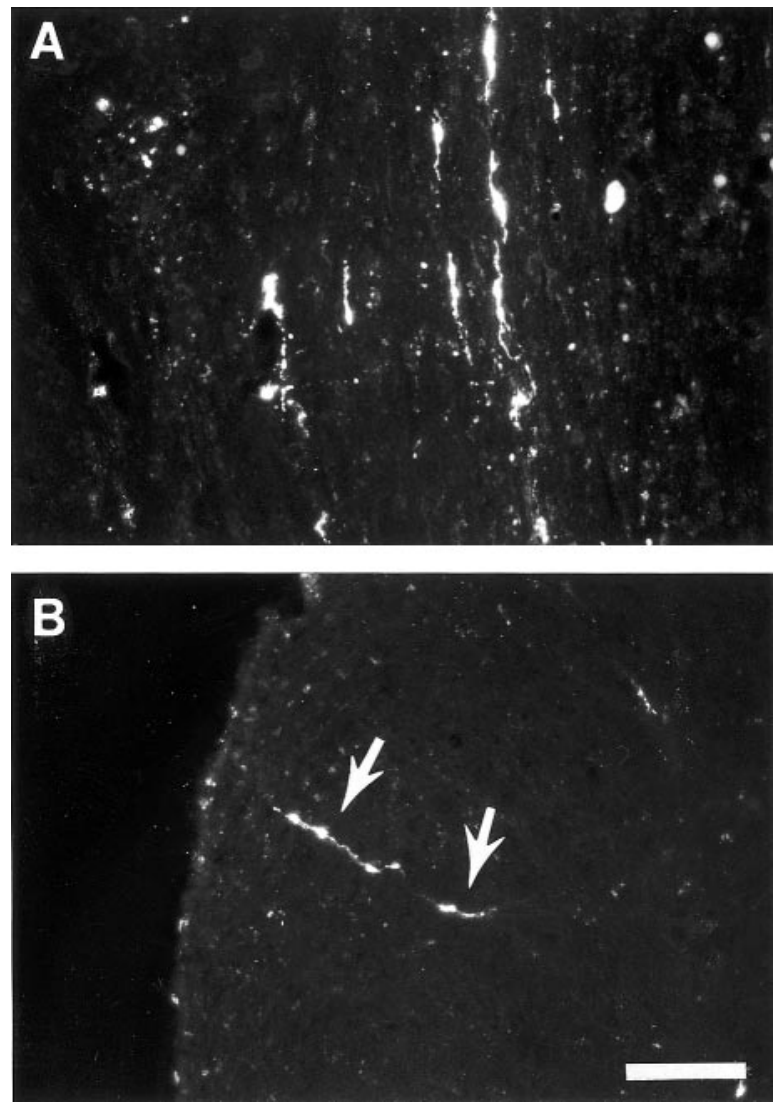

Figure 5. Fluoro-Ruby anterograde labeling of corticospinal neurons. Fluoro-Ruby was injected into the motor cortex 8 weeks after transplantation of fetal spinal cord tissue and neurotrophin administration. Animals survived for $10 \mathrm{~d}$ and were killed. Fluorescent micrographs show fibers labeled caudal to the transection site in longitudinal sections from thoracic cord $(A)$ and transverse sections from lumbar cord $(B)$. Scale bar, $100 \mu \mathrm{m}$. Arrows indicate labeled corticospinal axons traveling toward the gray matter.

white matter of caudal host spinal cord. Interestingly, axonal growth was not restricted to serotonergic pathways. Immunocytochemical labeling for noradrenergic axons showed similar patterns of regrowth. In addition, anterograde labeling of corticospinal axons indicated that, in the presence of either BDNF or NT-3, corticospinal axons were able to regrow across the transplant back into the host spinal cord caudal to the transplant. Retrograde labeling studies revealed that red nucleus, locus ceruleus, lateral vestibular, reticular, and raphe neurons are all capable of regrowth after injury and delayed transplantation with neurotrophins.

No particular intervention to alter the myelin-associated neurite growth inhibitors was used in this study. The reasons for greater axonal growth, especially within host white matter, are not clear. It is possible that some of the inhibitory influences associated with the mature CNS are downregulated at chronic intervals after injury. Certainly, myelin-associated neurite growth inhibitors are one class of molecules that restrict growth in the mature CNS (Schnell and Schwab, 1990, 1993; McKerracher et al., 1994; Mukhopadhyay et al., 1994; Thallmair et al., 1998). Blocking the influence of these inhibitors leads to increases in both regenerative growth of damaged pathways (Caroni and Schwab, 1988; Schwab et al., 1993) and sprouting of undamaged pathways (Thallmair et al., 1998; Z'Graggen et al., 1998). Both

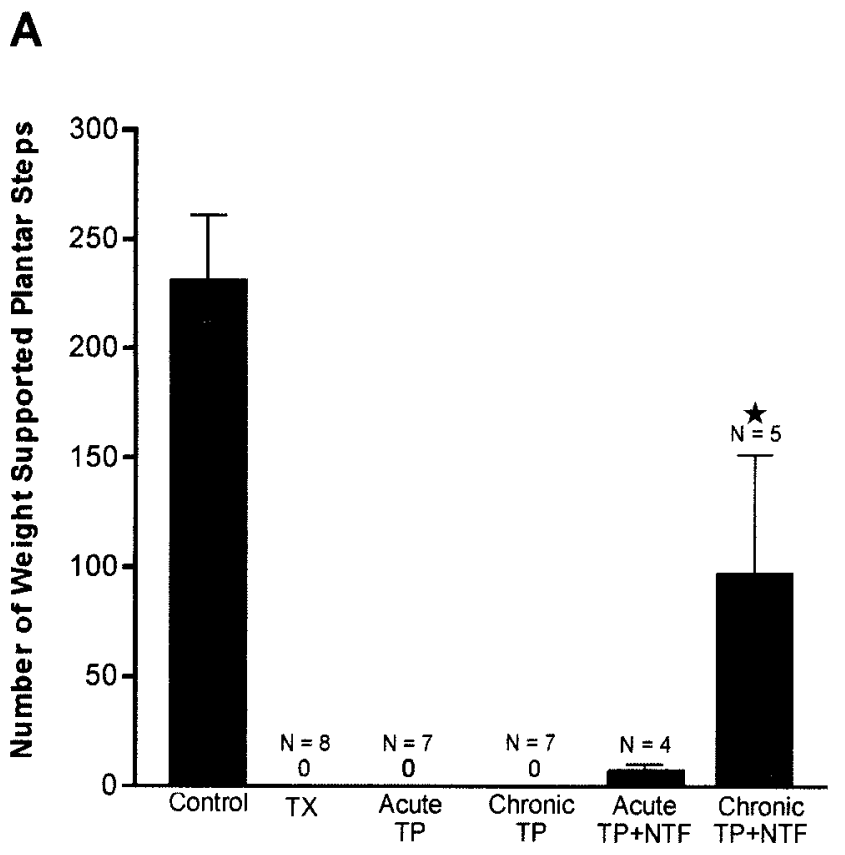

B

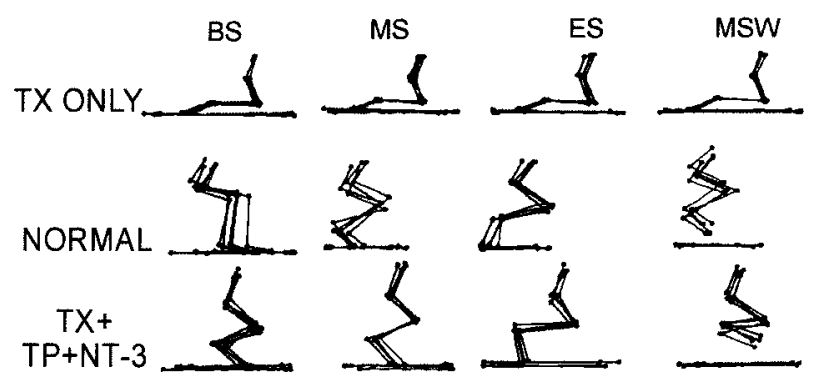

Figure 6. A, Histogram comparing number of weight-supported plantar steps $( \pm \mathrm{SD})$ on a treadmill in animals with a transection $(T X)$ only, with a transplant (Acute TP), with a delayed transplant (Chronic TP), with acute administration of transplant and neurotrophins $($ Acute TP $+N T F)$, or with delayed administration of transplant and NTF (Chronic TP + $N T F$ ). Animals with delayed administration of transplant and NTF had significantly more steps than those with acute administration of transplant and NTF ( $\star p<0.001$; ANOVA; Tukey's multiple comparison test). $B$, Kinematic analysis of hindlimb step cycles using the Peak Performance System for transection only (TX ONLY), normal, and delayed transplant with NT-3 $(T X+T P+N T-3)$. Bony landmarks for pelvis, hip, knee, ankle, and fifth metatarsal were digitized directly from videotapes. $B S$, Beginning of stance; $M S$, middle stance; $E S$, end of stance; $M S W$, midswing. The horizontal line below each stick figure represents the surface of the treadmill.

forms of plasticity lead to improvements in motor function (Bregman et al., 1995; Thallmair et al., 1998; Z'Graggen et al., 1998). The growth of axons in both gray and white matter within host spinal cord caudal to the transection suggests that some of the inhibitory influences associated with astrocytes (McKeon et al., 1995; Hoke and Silver, 1996; Davies et al., 1997; Fitch and Silver, 1997a,b) or myelin (Caroni and Schwab, 1988; Schnell and Schwab, 1990, 1993; Schwab et al., 1993; McKerracher et al., 1994; Mukhopadhyay et al., 1994) may be downregulated and present less of a barrier to the regrowth of axons after chronic injury. Studies by Silver and colleagues (Davies et al., 1997) suggest that, 
A
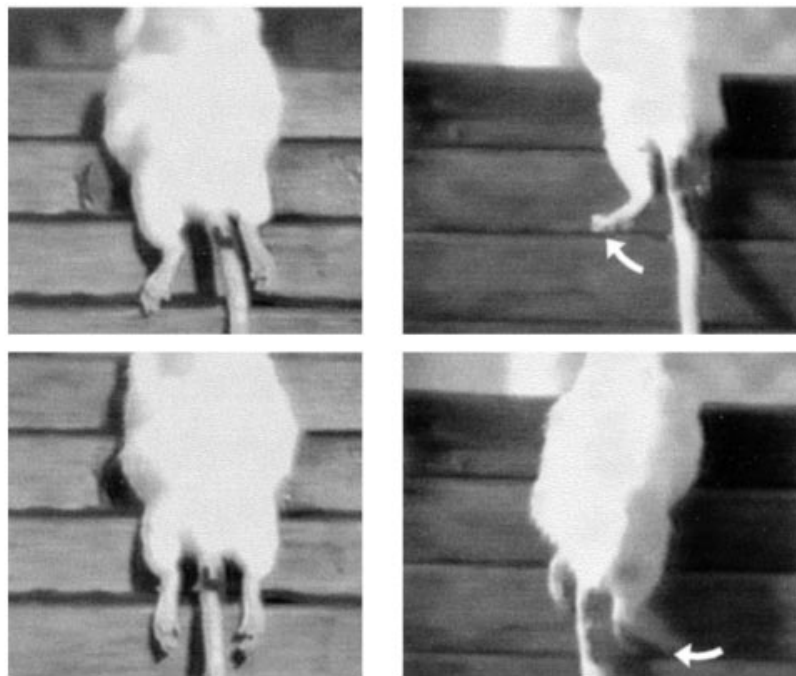

B

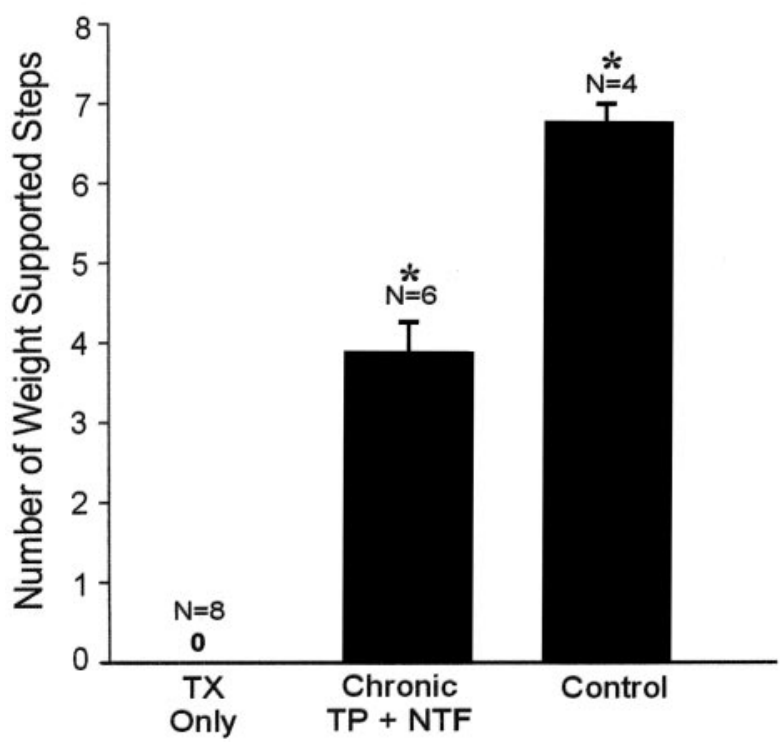

Figure 7. Stair ascension. $A$, Sequential video frames (interval, 27 frames) of a transection only animal (left panels) and transection with delayed transplant and neurotrophins (right panels) during stair ascension 2 months after injury. Animals are represented during best performances. Note that the transection only animals show no weight support on the stairs; hindlimbs are dragged passively behind the body. Animals that receive a delayed transplant with neurotrophins demonstrate bilateral weight support, plantar foot placement (see arrows), and coordinated forelimb-hindlimb stepping during stair climbing. $B$, Histogram comparing mean $\pm \mathrm{SD}$ total number of weight-supported steps during stair ascension on best day motor performance. Transection only (TX Only) animals showed no weight-supported stepping during stair climbing. Animals that received delayed transplants with neurotrophins (Chronic TP + $N T F)$ had significantly more weight-supported steps $(p<0.001$; ANOVA; Tukey's multiple comparison test).

in regions in which there is minimal direct damage or glial scarring (and its associated upregulation of proteoglycans within the extracellular matrix), some axons are able to grow long distances in adult myelinated white matter tracts. Neurotrophins themselves can also alter the response of neurons to myelin. Studies by Filbin and colleagues (Cai et al., 1999) show that exposure of neurons to neurotrophins in vitro, before they encounter the inhibitory influence of myelin-associated glycoproteins or myelin, increases the amount of neurite outgrowth via a cAMP-dependent mechanism.

It is clear that environmental factors play a role in restricting axonal growth within a mature CNS environment, because mature neurons can extend axons long distances within a peripheral nerve graft but terminate shortly after reentering a CNS environment (Aguayo et al., 1979, 1981; Richardson et al., 1980, 1984; David and Aguayo, 1981, 1985). A recent study by Ramon-Cueto et al. (2000) demonstrates long-distance motor axon regeneration across a spinal cord transection site in the presence of olfactory ensheathing cells, a cell type shown previously to be permissive for corticospinal axon regeneration ( $\mathrm{Li}$ et al., 1998). Recent studies in our laboratory show that the expression of proinflammatory cytokines is attenuated in the spinal cord when the lesion site is reexposed and the scar tissue is removed compared with levels of cytokine expression after a more acute injury (M. Nakamura, R. Houghtling, L. MacArthur, B. M. Bayer and B. S. Bregman, unpublished observations). Thus, the environment at the injury site may become more favorable for axonal growth over time after injury compared with the acutely injured spinal cord, and in the presence of fetal spinal cord transplants and neurotrophins, support regeneration of supraspinal neurons.

It is likely that the differences between acute and delayed transplant injury conditions are not restricted to the environment alone. Rather, there may be differences in the ability of neurons themselves to mount a regenerative response. The process of reexposing the lesion site 2 weeks after injury and clearing away the glial scar at the injury site before the placement of the transplant may actually elicit a "conditioning lesion" (Richardson and Issa, 1984; Neumann and Woolf, 1999) such as that seen in dorsal root ganglia. That is, neurons that have been injured previously may be primed to upregulate cellular and molecular programs associated with axonal growth. After axotomy at a distance from the cell body, CNS neurons fail to upregulate regeneration-associated cell programs (Jenkins et al., 1993). We showed previously that, after acute spinal cord injury, transplants and neurotrophic factors upregulate c-Jun expression in the cell bodies of descending axotomized CNS neurons (Broude et al., 1997, 1999). This is associated with increases in the distance and amount of regrowth within the transplant tissue itself (Bregman et al., 1997b), suggesting that neurotrophins upregulate cellular programs associated with regeneration (Herdegen et al., 1997; Bregman et al., 1998). Whether a second lesion augments this response remains to be determined.

The growth of supraspinal axons across the transplant and back into the host spinal cord caudal to the lesion was dependent on the presence of exogenous neurotrophic support. Without the neurotrophins, only propriospinal axons were able to reestablish connections across the transplant. Studies using peripheral nerve or Schwann cell grafts have shown that some anatomical connectivity can be restored across the injury site, particularly under the influence of neurotrophins (Xu et al., 1995a,b; Cheng et al., 1996; Ye and Houle, 1997). Without neurotrophin treatment, brainstem axons do not enter the graft (Xu et al., 1995a,b; Ye and Houle, 1997). Similarly, cells genetically modified to secrete neurotrophins and transplanted into the spinal cord influence the axonal growth of specific populations of spinally projecting neurons (Tuszynski et al., 1996, 1997; Liu et al., 1999). Together, these 
studies support a role for neurotrophic factors in the repair of the mature CNS.

The regrowth of supraspinal and propriospinal input across the transection site was associated with consistent improvements in hindlimb locomotor function. Animals performed alternating and reciprocal hindlimb stepping with plantar foot contact to the treadmill or stair during ascension. Furthermore, they acquired hindlimb weight support and demonstrated appropriate postural control for balance and equilibrium of all four limbs. After spinal cord injury in the adult, the circuitry underlying rhythmic alternating stepping movements is still present within the spinal cord caudal to the lesion but is now devoid of supraspinal control.

We show here that restoring even relatively small amounts of input allows supraspinal neurons to access the spinal cord circuitry. Surprisingly, the variability in functional improvement did not directly relate to fiber density, suggesting that restoring some input to the spinal pattern generator after spinal cord transection, rather than total fiber numbers, is a better predictor for recovery of hindlimb locomotion. Removing the reestablished supraspinal input after recovery (by retransection rostral to the transplant) abolished the recovery and abolished the serotonergic fibers within the transplant and spinal cord caudal to the transplant. This suggests that at least some of the recovery observed is attributable to reestablishing supraspinal input across the transplant rather than a diffuse influence of the transplant on motor recovery. It is unlikely, however, that the greater recovery of function in animals that received delayed transplant and neurotrophins is attributable solely to the restoration of supraspinal input. Recent work by Ribotta et al. (2000) suggests that segmental plasticity within the spinal cord contributes to weight support and bilateral foot placement after spinal cord transection. This recovery of function occurs after transplants of fetal raphe cells into the adult spinal cord transected at T11. Recovery of function appears to require innervation of the L1-L2 segments with serotonergic fibers, and importantly, animals require external stimulation (tail pinch) to elicit the behavior. In the current study, animals with transection only did not develop stepping over ground or on the treadmill without tail pinch, although the transplant and neurotrophin-treated groups did so without external stimuli. Therefore, both reorganization of the segmental circuitry and partial restoration of supraspinal input presumably interact to yield the improvements in motor function observed.

We do not know how long after the initial injury mature CNS neurons maintain the ability to regrow under favorable conditions. When chronically injured neurons were reinjured closer to the cell body and presented with a blind-ended peripheral nerve graft, some populations of CNS neurons were able to regrow, even at long postinjury intervals. This regrowth was increased by the application of neurotrophins (Houle, 1991; Houle et al., 1997; Ye and Houle, 1997). In this study, rats that received transplants and neurotrophins 4 weeks after spinal cord transection showed similar growth of raphe-spinal neurons, although total fiber length was somewhat reduced and there was greater variability between animals. Animals also showed recovery of function similar to those that received treatment at 2 weeks (data not shown), suggesting that these neurons retain their regenerative capacity for sustained periods after injury.

In summary, the therapeutic intervention of tissue transplantation and exogenous neurotrophin support leads to improvements in propriospinal input across the transplant into the host caudal cord and a concomitant improvement in locomotor function. Paradoxically, delaying these interventions for several weeks after a spinal cord transection leads to dramatic improvements in recovery of function and a concomitant restoration of supraspinal input into the host caudal spinal cord. These findings suggest that opportunity for intervention after spinal cord injury may be far greater than originally envisioned and that CNS neurons with long-standing injuries may be able to reinitiate growth, leading to improvement in motor function.

\section{REFERENCES}

Aguayo A, David S, Richardson P, Bray G (1979) Axonal elongation in peripheral and central nervous system transplants. Adv Cell Neurobiol 3:215-234.

Aguayo A, David S, Bray G (1981) Influences of the glial environment on the elongation of axons after injury: transplantation studies in adult rodents. J Exp Biol 95:231-240.

Basso DM, Beattie MS, Bresnahan JC (1995) A sensitive and reliable locomotor rating scale for open field testing in rats. J Neurotrauma 12:1-21.

Bregman B (1987a) Development of serotonin immunoreactivity in the rat spinal cord and its plasticity after neonatal spinal cord lesions. Dev Brain Res 34:245-263.

Bregman B (1987b) Spinal cord transplants permit the growth of serotonergic axons across the site of neonatal spinal cord transection. Dev Brain Res 34:265-279.

Bregman B (1994) Recovery of function after spinal cord injury: transplantation strategies. In: Functional neural transplantation (Dunnett $\mathrm{S}$, Bjorklund A, eds), pp 489-529. New York: Raven.

Bregman B, Goldberger M (1982) Anatomical plasticity and sparing of function after spinal cord damage in neonatal cats. Science 217:553-555

Bregman B, McAtee M (1993) Embryonic CNS tissue transplantation for studies of development and regeneration. Neuroprotocols 3:17-27.

Bregman B, Kunkel-Bagden E, McAtee M, O'Neill A (1989) Extension of the critical period for developmental plasticity of the corticospinal pathway. J Comp Neurol 282:355-370.

Bregman B, Kunkel-Bagden E, Reier P, Dai H, McAtee M, Gao D (1993) Recovery of function after spinal cord injury: Mechanisms underlying transplant-mediated recovery of function differ after spinal cord injury in newborn and adult rats. Exp Neurol 123:3-16.

Bregman B, Kunkel-Bagden E, Schnell L, Dai H, Gao D, Schwab M (1995) Recovery from spinal cord injury mediated by antibodies to neurite growth inhibitors. Nature 378:498-501.

Bregman B, Diener P, McAtee M, Dai H, James C (1997a) Intervention strategies to enhance anatomical plasticity and recovery of function after spinal cord injury. Adv Neurol 72:257-275.

Bregman B, McAtee M, Dai H, Kuhn P (1997b) Neurotrophic factors increase axonal growth after spinal cord injury and transplantation in the adult rat. Exp Neurol 148:475-494.

Bregman B, Broude E, McAtee M, Kelley M (1998) Transplants and neurotrophic factors prevent atrophy of mature CNS neurons after spinal cord injury. Exp Neurol 149:13-27.

Broude E, McAtee M, Kelley M, Bregman B (1997) c-Jun expression in adult rat dorsal root ganglion neurons: differential response after central or peripheral axotomy. Exp Neurol 148:367-377.

Broude E, McAtee M, Kelley M, Bregman B (1999) Fetal spinal cord transplants and exogenous neurotrophic support enhanced c-Jun expression in axotomized neurons after spinal cord injury. Exp Neurol 155:65-78.

Cai D, Shen Y, DeBellard M, Tang S, Filbin M (1999) Prior exposure to neurotrophins blocks inhibition of axonal regeneration by MAG and myelin via a cAMP-dependent mechanism. Neuron 22:89-101.

Caroni P, Schwab M (1988) Antibody against myelin-associated inhibitor of neurite growth neutralizes nonpermissive substrate properties of CNS white matter. Neuron 1:85-96.

Cheng H, Cao Y, Olson L (1996) Spinal cord repair in adult paraplegic rats: partial restoration of hind limb function. Science 273:510-513.

Chong M, Fitzgerald M, Winter J, Hu-Tsai M, Emson P, Wiese U, Woolf C (1992) GAP-43 mRNA in rat spinal cord and dorsal root ganglia neurons: developmental changes and re-expression following peripheral nerve injury. Eur J Neurosci 4:883-895.

David S, Aguayo A (1981) Axonal elongation into peripheral nervous system "bridges" after central nervous system injury in adult rats. Science 214:931-933.

David S, Aguayo A (1985) Axonal regeneration after crush injury of rat central nervous system fibres innervating peripheral nerve grafts. J Neurocytol 14:1-12.

Davies S, Fitch M, Memberg S, Hall A, Raisman G, Silver J (1997) Regeneration of adult axons in white matter tracts of the centra nervous system. Nature 390:680-683.

Fitch M, Silver J (1997a) Activated macrophages and the blood-brain barrier: inflammation after CNS injury lead to increases in putative inhibitory molecules. Exp Neurol 148:587-603. 
Fitch M, Silver J (1997b) Glial cell extracellular matrix: boundaries for axon growth in development and regeneration. Cell Tissue Res 290:379-384

Fitzgerald M, Reynolds M, Benowitz L (1991) GAP-43 expression in the developing rat lumbar spinal cord. Neuroscience 41:187-199.

Hasan S, Kierstead H, Muir G, Steeves J (1993) Axonal regeneration contributes to repair of injured brainstem-spinal neurons in embryonic chick. J Neurosci 13:492-507.

Herdegen T, Skene J, Bahr M (1997) The c-Jun transcription factorbipotental mediator of neuronal death, survival and regeneration. Trends Neurosci 20:227-231.

Hoke A, Silver J (1996) Proteoglycans and other repulsive molecules in glial boundaries during development and regeneration of the nervous system. Prog Brain Res 108:149-163.

Houle J (1991) Demonstration of the potential for chronically injured neurons to regenerate axons into intraspinal peripheral nerve grafts. Exp Neurol 113:1-9.

Houle J, Ye J, Kane C (1997) Axonal regeneration by chronically injured supraspinal neurons can be enhanced by exposure to insulin-like growth factor, basic fibroblast growth factor or transforming growth factor beta. Restor Neurol 10:205-215.

Howland D, Bregman B, Tessler A, Goldberger M (1995) Transplants enhance locomotion in neonatal kittens whose spinal cords are transected: a behavioral and anatomical study. Exp Neurol 135:123-145.

Jakeman L, Reier P (1991) Axonal projections between fetal spinal cord transplants and the adult rat spinal cord: a neuroanatomical tracing study of local interactions. J Comp Neurol 307:311-334.

Jenkins R, Tetzlaff W, Hunt S (1993) Differential expression of immediate early genes in rubrospinal neurons following axotomy in rat. Eur J Neurosci 5:203-209.

Keirstead H, Dyer J, Sholomenko G, McGraw J, Delaney K, Steeves J (1995) Axonal regeneration and physiological activity following transection and immunological disruption of myelin within the hatchling chick spinal cord. J Neurosci 15:6963-6974.

Keirstead H, Pataky D, McGraw J, Steeves J (1997) In vivo immunological suppression of spinal cord myelin development. Brain Res Bull 44:727-734.

Kunkel-Bagden E, Bregman B (1990) Spinal cord transplants enhance the recovery of locomotor function after spinal cord injury at birth. Exp Brain Res 81:25-34.

Kunkel-Bagden E, Dai H, Bregman B (1993) Methods to assess the development and recovery of locomotor function after spinal cord injury in rats. Exp Neurol 119:153-164.

Li Y, Field P, Raisman G (1998) Regeneration of adult rat corticospinal axons induced by transplanted olfactory ensheathing cells. J Neurosci 18:10514-10524.

Liu Y, Kim D, Himes B, Chow S, Schallert T, Murray M, Tessler A, Fischer I (1999) Transplants of fibroblasts genetically modified to express BDNF promote regeneration of adult rat rubrospinal axons and recovery of forelimb function. J Neurosci 19:4370-4387.

McKeon R, Schreiber R, Rudge J, Silver J (1991) Reduction of neurite outgrowth in a model of glial scarring following CNS injury is correlated with the expression of inhibitory molecules on reactive astrocytes. J Neurosci 11:3398-3411.

McKeon R, Hoke A, Silver J (1995) Injury-induced proteoglycans inhibit the potential for laminin-mediated axon growth on astrocytic scars. Exp Neurol 136:32-43.

McKerracher L, David S, Jackson D, Kottis V, Dunn R, Braun P (1994) Identification of myelin-associated glycoprotein as a major myelinderived inhibitor of neurite growth. Neuron 13:805-811.

Miya D, Giszter S, Mori F, Adipudi V, Tessler A, Murray M (1997) Fetal transplants alter the development of function after spinal cord transection in newborn rats. J Neurosci 17:4856-4872.

Mukhopadhyay G, Doherty P, Walsh F, Crocker P, Filbin M (1994) A novel role for myelin-associated glycoprotein as an inhibitor of axonal regeneration. Neuron 13:757-767.

Neumann S, Woolf C (1999) Regeneration of dorsal column fibers into and beyond the lesion site following adult spinal cord injury. Neuron 23:83-91.

Nicholls J, Saunders N (1996) Regeneration of immature mammalian spinal cord after injury. Trends Neurosci 19:229-234.

Pindzola R, Doller C, Silver J (1993) Putative inhibitory extracellular matrix molecules at the dorsal root entry zone of the spinal cord during development and after root and sciatic nerve lesions. Dev Biol 156:34-48.

Ramon-Cueto A, Cordero MI, Santos-Benito F, Avila J (2000) Functional recovery of paraplegic rats and motor axon regeneration in their spinal cords by olfactory ensheathing glia. Neuron 25:425-435.

Reier P, Houle J, Jakeman L, Winialski D, Tessler A (1988) Transplantation of fetal spinal cord tissue into acute and chronic hemisection and contusion lesions of the adult spinal cord. Prog Brain Res 78:173-179.

Ribotta MG, Provencher J, Feraboli-Lohnherr D, Rossignol S, Privat A, Orsal D (2000) Activation of locomotion in adult chronic spinal rats is achieved by transplantation of embryonic raphe cells reinnervating a precise lumbar level. J Neurosci 20:5144-5152.

Richardson P, Issa V (1984) Peripheral nerve injury enhances central regeneration of primary sensory neurons. Nature 309:791-793.

Richardson P, McGuinness U, Aguayo A (1980) Axons from CNS neurones regenerate into PNS grafts. Nature 284:264-265.

Richardson P, Issa V, Aguayo A (1984) Regeneration of long spinal axons in the rat. $\mathrm{J}$ Neurocytol 13:165-182.

Savio T, Schwab M (1990) Lesioned corticospinal tract axons regenerate in myelin-free rat spinal cord. Proc Natl Acad Sci USA 87:4130-4133.

Schnell L, Schwab M (1990) Axonal regeneration in the rat spinal cord produced by an antibody against myelin-associated neurite growth inhibitors. Nature 343:269-272.

Schnell L, Schwab M (1993) Sprouting and regeneration of lesioned corticospinal tract fibres in the adult rat spinal cord. Eur J Neurosci 5:1156-1171.

Schwab M, Schnell L (1991) Channeling of developing rat corticospinal tract axons by myelin-associated neurite growth inhibitors. J Neurosci 11:709-721.

Schwab M, Kapfhammer J, Bandtlow C (1993) Inhibitors of neurite growth. Annu Rev Neurosci 16:565-595.

Thallmair M, Metz G, Z'Graggen W, Raineteau O, Kartje G, Schwab M (1998) Neurite growth inhibitors restrict plasticity and functional recovery following corticospinal tract lesions. Nat Neurosci 1:124-131.

Tuszynski M, Gabriel K, Gage F, Suhr S, Meyer S, Rosetti A (1996) Nerve growth factor delivery by gene transfer induces differential outgrowth of sensory, motor, and noradrenergic neurites after adult spinal cord injury. Exp Neurol 137:157-173.

Tuszynki M, Murai K, Blesch A, Grill R, Miller I (1997) Functional characterization of NGF secreting cell grafts to the acutely injured spinal cord. Cell Transplant 6:361-368.

Xu X, Geunard V, Kleitman N, Bunge M (1995a) Axonal regeneration into Schwann cell-seeded guidance channels grafted into transected adult rat spinal cord. J Comp Neurol 351:145-160.

Xu X, Guenard V, Kleitman N, Aebischer P, Bunge M (1995b) A combination of BNDF and NT-3 promotes supraspinal axonal regeneration into Schwann cell grafts in adult rat thoracic spinal cord. Exp Neurol 134:261-272.

Ye J, Houle J (1997) Treatment of the chronically injured spinal cord with neurotrophic factors can promote axonal regeneration from supraspinal neurons. Exp Neurol 143:70-81.

Z'Graggen W, Metz G, Kartje G, Thallmair M, Schwab M (1998) Functional recovery and enhanced corticofugal plasticity after unilateral pyramidal tract lesion and blockade of myelin-associated neurite growth inhibitors in adult rats. J Neurosci 18:4744-4757. 